\title{
Evaluation, Economics, and Sustainable Development
}

\begin{abstract}
This introductory chapter opens the discussion on applying economic tools for evaluating sustainable development. It sets out the focal argument of this book that the current approach to development evaluation, which primarily assesses the value added of growth with only a cursory glance given to issues of inclusion, environmental stewardship, and good governance, needs to evolve to more thoroughly account for these critical issues.
\end{abstract}

Keywords Economic growth • Inclusion • Environment • Governance • Climate change

One of the great mistakes is to judge policies and programs by their intentions rather than their results.

Milton Friedman

Evaluation has a rich history in informing work on economic development. Both countries and financiers have used evaluations to improve their work on development projects, individual sectors, and sometimes the

The original version of this chapter was revised. An erratum to this chapter can be found at https://doi.org/10.1007/978-981-13-6389-4_6 
economy. Multilateral, bilateral, and United Nations development finance agencies have funded evaluations of their work in countries and regions over the years, and most now have evaluation offices, many of them independent in their mandate (Picciotto 2013). Colombia, Mexico, South Africa, the United Kingdom, and the United States are among the growing number of nations that have strengthened evaluation capacity over the years (Thomas and Luo 2012).

A premise in all this is that different methods of evaluation in varying contexts can help make development programs more effective (OECD 2010). Evaluation assumes great importance when competition for scarce resources increases. In times of crises, such as the 2008 global financial crisis, there was demand for information on how government-funded programs were performing. Policy-makers and the public need to know which programs are likely to achieve a high development impact and which are not, and evaluation can try to provide that, as well as lessons for improving programs' performance.

Different approaches have tried to track the results of interventions. Impact evaluation (IE) has been increasingly applied to programs in social areas, such as education, health, and social protection (Sabet and Brown 2018). Infrastructure investments, for example, in energy, transport, and water supply, have usually been put to the test using cost-benefit analysis (CBA). Development agencies have assessed how well programs are delivering on the objectives they set out using objectives-based evaluation (OBE).

Evaluation intersects with economic analysis when assessing economic development and also related social policy objectives such as investing in people. Economic analysis has long been applied to influence development policies at the macroeconomic and microeconomic levels (IEG 2010,2012 ). There is a vast body of evidence on the economic costs and returns of having greater openness in trade policy (see, e.g., Lukauskas et al. 2013). Analysis of the effects of trade liberalization on agriculture, industry, or services provides grounds for policy reform. Similarly, a great deal of empirical work has tried to shed light on the economic returns to individuals or households from having more education (for instance, Hanushek et al. 2006; World Bank 2006).

One overarching objective of this book is to illustrate how evaluation and economic tools can be applied more meaningfully with reference to how development goals are being furthered. Development is tied to human, social, and environmental concerns and impacts on future generations. This idea of "sustainable development" encapsulates the principal considerations of policy and action. By the very nature of sustainable 
development, environmental protection and climate change become key aspects of economic growth.

Development evaluation must find ways to assess sustainable development and not just aspects of economic growth, as is often done. Specifically, the socio-political and economic landscapes of nations need to factor in goals of promoting greater social inclusion, environmental protection, or better governance. By bringing economics and evaluation together, we can better see the results of interventions through the lens of sustainable development.

A critical question that arises is the "evaluability" of complex sustainable development issues such as climate change, social inclusion, and good governance. There is recognition that these issues present major challenges to traditional objectives-based evaluative enquiry (McGrail 2014). Evaluating projects and interventions aimed at addressing them thus requires reformulating evaluation goals and objectives, rethinking the framing and design of evaluations, and blurring of evaluation boundaries from being intervention-focused to being more aggregative.

Explicating the connection between evaluation and economic policy analysis is another overall objective of this book. The payoffs to forging connections between economics and evaluation can be high, but opportunities have not been adequately seized, and economics and evaluation have not been brought together sufficiently. Often bureaucratic motivations have kept work in separate disciplines. Limitations of methods of analysis and data availability have also stood in the way of stronger interactions between the disciplines.

The interlinkages among strands of policy issues are complex, both with respect to the challenges they pose and the opportunities they present. This is not only the case for broader issues in economic development but also for interventions, which can be individual projects or nationallevel programs or policies. Economic motivations interact with social and political forces in development interventions. For instance, trade liberalization connects at the same time with sources of welfare gains and welfare losses to specific groups in varying degrees, which then affect the feedback on trade liberalization policies and democratic decisions made.

Bringing economics and evaluation together can create better interactive links among policy areas, which, when exploited, illuminate aggregative issues of concern in development. Individual project or sectoral analyses are valuable, and they are essential building blocks for assessing crosscutting areas. However, if they are relied on to the exclusion of other tools, as is often done, evaluation can fall short of its promise of informing policy directions. 


\section{Evaluating Sustainable Development}

As development challenges become more complex, replicating what worked in the past-even projects rated as highly successful-is no guarantee of continuing success. Continuing development problems, such as groundwater depletion, quality of education, and income distribution, remain intractable. Previous solutions may no longer suffice given a changing physical, social, and economic environment. New problems, such as rising incidence of non-communicable diseases, environmental degradation, and climate change, add to the premium for innovation in projects and development portfolio.

A recent review summarizes eight challenges in development that evaluation would do well to confront and address (Basu et al. 2016). These issues resonate as priorities for development evaluation: economic growth as a means to well-being; inclusive growth; environmental care, including climate change; market-state balance and regulation; macroeconomic stability; technological change; social norms; and changes in global economic forces.

Much of evaluation of projects and programs directly or indirectly deals with the impact on efficiency and effectiveness of economic growth. There is a great deal of good project evaluations as well as some evaluation studies considering the economy-wide impact of a financial crisis (e.g., IEO 2014), trade liberalization, or other changes on growth. But the current approaches primarily deal with value addition in terms of economic growth, with only a limited look at income distribution, environmental protection, and good governance.

The challenge for evaluation is integrating environmental, social, and institutional aims while assessing growth. The United Nations Sustainable Development Goals (SDGs) capture these dimensions in the form of targets (United Nations 2016). Following SDGs and empirical results on development attributes (see, e.g., World Bank 1991, United Nations 2016), this book takes sustainable development to mean a combination of economic growth, social inclusion, and environmental stewardship underpinned by good governance.

As illustrated in Fig. 1.1, these developmental issues are distinct but also interact with each other.

By the nature of the measurement of improvements, economic growth is rightly captured in evaluation. Broadening of the focus of evaluation from the pace of growth to the quality and impact of growth calls for 
Fig. 1.1 Interactions among sustainable development issues. (Source: Authors' illustration)

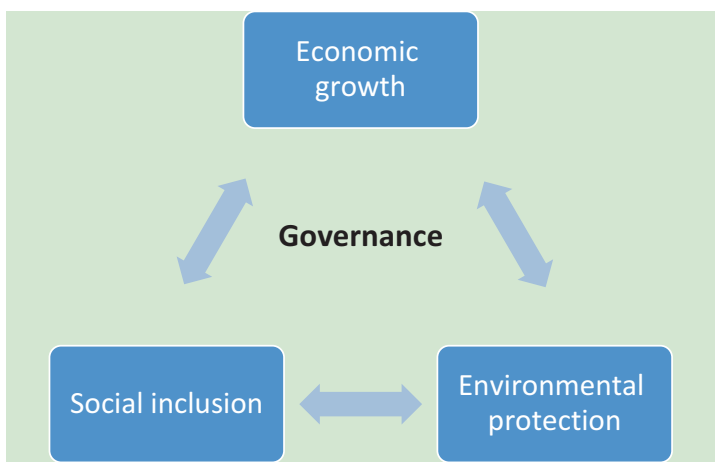

policy to inter alia address inclusive growth. Policy-making would want to see if people are left behind, unemployment is tackled, and inadequate health care and lack of access to education are dealt with. These topics merit evaluation, as evaluation agendas of various organizations indicate.

Measurement and analysis of extreme poverty have received considerable attention, in part because poverty reduction mirrors income growth (holding income distribution constant). The period of the Millennium Development Goals (MDGs) saw a sizable decline in extreme poverty (Ravallion 2013), but serious challenges remain especially as hazards of nature or food price shocks can easily put vulnerable populations back into poverty. Income distribution has worsened in many countries although evaluations do not take up distributional issues often.

Environmental protection is central to sustainable development. At the national level, income growth that comes at the cost of environmental damage, such as air and water pollution, is proving to be unsustainable. Beijing and New Delhi, the capital cities of the world's most populous countries, suffer from dangerously high levels of air pollution. Globally, climate change is a threat to health, livelihoods, and habitats. Climate change mitigation and adaptation need to be integral to development policy, and their evaluation, difficult as it may be, needs to become part of the tool kit.

The interaction among attributes of sustainable development comes through strongly in the case of climate change. For instance, for infrastructure investments to generate lasting growth, they need to take into account climate effects. Energy policies impact the adoption of renewable and clean energy supply on the one side and the use of polluting fossil 
fuels on the other. A few countries have launched cap-and-trade schemes for carbon emissions, and a few others have started levying a carbon tax on fuels. More must be done, and these efforts need to be evaluated to strengthen outcomes.

The role of institutions and governance is another overarching dimension that calls for updates to the evaluation agenda. The functioning of institutions is being addressed in varying degrees by evaluation groups, including those assessing organizational units or corporate entities and strategies or directions. Greater rigor can be introduced into such work, and the role of public goods and market externalities given greater attention.

A continuing question is if the pursuit of sustainable development will come at the expense of economic growth. The neglect of environmental externalities in policy-making would seem to suggest that it views economic growth on the one side and environmental care and climate action on the other as conflictive. Evaluations might shed light on the possibility that climate mitigation and other sustainability measures might contribute to continuing economic growth and, by the same token, turn them into market opportunities.

In this book, we provide evidence from the experience of International Finance Corporation (IFC) and Asian Development Bank (ADB) that economic returns and sustainable development likely go together (Chap. 4 ). The key point is not only that economic growth, environmental protection, and social sustainability can go hand in hand but also that it may be hard to sustain growth without social inclusion and environmental care.

Evaluating sustainable development can have important payoffs in two ways. It can help keep the eye on broader development goals, such as the SDGs. It can also help to adopt efficient and effective policies and investments to further sustainable outcomes. There is likely underinvestment in evaluating development effectiveness in general (Ravallion 2009). On top of that, the value of evaluating sustainability suggests the need for even stronger evaluation efforts.

Considering sustainability in evaluation has usually meant different things to different people. One way of thinking is whether a project or an intervention itself is sustained into the future, especially after the funding for it has ended. This of course has broader implications in that if the project is not sustained, its benefits too may not last.

A second approach is to look at this latter aspect directly, that is, assessing the extent to which the benefits of a project, program, or policy are 
maintained after formal support has ended. Development Assistance Committee's (DAC) evaluation framework includes sustainability as one of its five criteria of evaluation (see Chap. 4). Under this criterion, financial and institutional and sometimes environmental care too are considered.

A third approach, which is the focus of this book, is to think of the impact of a project or other forms of intervention on sustainable development (see IEU 2018 for examples). In so doing sustainable development might be taken to mean "Development that meets the needs of the present without compromising the ability of future generations to meet their own needs" (Brundtland 1987).

This approach might in part be synonymous with environmental stewardship, as this is a highly vulnerable aspect of efforts that target economic growth. But, under the SDGs, sustainability goes much further than the environment, although the stress on the environment and climate is much stronger than under the MDGs. In addition to the environment, the SDGs emphasize social inclusion and governance (Box 1.1).

The term "sustainability," which has roots in forest management, might refer to human-ecosystem balance, while "sustainable development" refers to underlying temporal processes (Shaker 2015). It would be fair to say that policies aimed at sustainable development would promote the best use of resources to help meet human needs while protecting the integrity of the natural system, which in turn is essential for future human needs to be met.

\section{Box 1.1 Sustainable Development Goals}

The Sustainable Development Goals (SDGs) of the 2030 Agenda for Sustainable Development were adopted in September 2015 at the United Nations Sustainable Development Summit and officially came into force in January 2016. The goals were based on the lessons from the Millennium Development Goals (MDGs). In effect during 1990-2015, the MDGs had established a common platform to tackle extreme poverty and hunger, universal education, and better health. During that period, extreme poverty rate dropped from 47 percent to 14 percent, the number of out-of-school children of primary school age declined from 100 million to 57 million, and child mortality dropped from 12.7 million to 6 million (United Nations 2015). 
The SDGs place greater values than MDGs on building a sustainable world with environmental protection, social inclusion, and economic development. One of the new goals is to combat climate change and its impacts on public health, food and water security, migration, peace, and security. While MDGs were intended for lowincome countries, the new goals cannot be achieved without the efforts of all countries including high-income ones.

The 17 SDGs are no poverty; zero hunger; good health and wellbeing; quality education; gender equality; clean water and sanitation; affordable and clean energy; decent work and economic growth; industry, innovation, and infrastructure; reduced inequalities; sustainable cities and communities; responsible consumption and production; climate action; life below water; life on land; peace and justice strong institutions; and partnerships to achieve the goals.

At the global level, the achievement of SDGs is monitored using the global indicator framework developed by the Inter-agency and Expert Group on SDG Indicators, prepared in March 2015 at the session of the United Nations Statistical Commission. The Highlevel Political Forum, established in 2012, meets annually and serves as the main platform for follow-up and review of SDGs. The Forum offers a means to monitor the progress in each country and region, exchange the best practices, and to foster international cooperation.

A recent report (United Nations 2018) states that, while there has been some progress in the three years after the SDGs were implemented, progress has not been rapid enough for the targets to be achieved by 2030 . It reiterates that the challenges in achieving the ambitious goals are interrelated and integrated approaches need to be adopted. For example, proper management of wastewater is closely related with public health and the environment. It also highlights the crucial gaps in data from national statistical and data systems to monitor the progress toward the goals (United Nations 2018). There have also been some efforts to assess the synergies and trade-offs among the SDGs (Pradhan et al. 2017). 


\section{Economics-Evaluation InTERACTION}

Economic thinking in evaluation design pertains to reflecting more analytically about the relationship between the objectives of a program or intervention and the results. How a project or intervention is expected to achieve results depends on the underlying assumptions - on the validity of what economic theory and practice expect. An evaluation based on economic thinking begins by laying out a chain linking inputs to outputs, outcomes, and impacts for a given project.

To answer why the intervention worked or did not work, mapping out the results chain to test the underlying assumptions is key. Many of the events or conditions that are assumed to produce the desired outcomes might not be in place. Nor might the interventions function as expected, particularly in view of the growing complexity and interrelatedness of development programs. Assumptions need to be identified and tested in relation to the macroeconomic and political environments. Evaluation can unbundle the theory of change to review how an intervention might convert inputs and outputs into outcomes and impacts. Theory of change is an approach for evaluation grounded in the mechanics of social change, looking at goals and mapping backward to identify preconditions.

To be effective, evaluation needs to consider the links connecting inputs to outputs - and to outcomes and impacts (Fig. 1.2). This requires focusing on identifying what might be the right results, getting the appropriate measures, and providing lessons to enhance development effectiveness. To ensure some degree of objectivity, the results might revolve around commonly accepted and well-articulated development goals, such as the SDGs. The development community has tried to move from a focus on inputs and outputs to a consideration of outcomes and impacts, as has been seen in a series of events including the 2002 International Conference on Financing for Development in Monterrey, Mexico, which established the MDGs, and the 2008 Forum on Aid Effectiveness in Accra, Ghana. The adoption of the SDGs underscored the focus on getting results on the ground.

The focus on outcomes and impacts draws attention to the vital links in the results chain and to the complexity of attributing outcomes to particular inputs. Many factors influence results, including conditions outside the domain of the interventions. The findings of evaluations refer to and intersect with the full process of the development, from inputs to outputs, to outcomes, and to impacts relating to the interventions. By considering the development process in designing an evaluation, findings can have value not only retrospectively but also in real time and prospectively. 


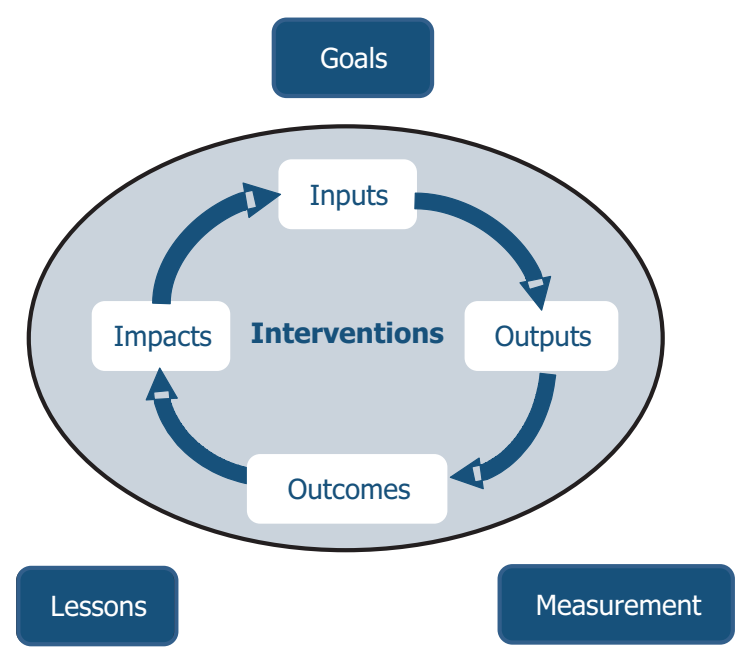

Fig. 1.2 Development process and the results chain. (Source: Authors' illustration)

Some evaluations have faced the criticism that they do not deal with unintended effects and complexities. Not only direct effects, such as the contribution of investment to economic growth, but also indirect effects, such as the influence of improved access to water and sanitation on girls' education, are to be considered. These latter links are often not considered, let alone quantified. The results chain must therefore consider the intended consequences of development activities and also the unintended impacts, such as the social dislocations caused by a road project or a water project, which can be just as important in urban and rural settings (Tolley et al. 1979). It is not enough to measure only the intended results, because the unintended ones may provide unexpected benefits or costs. Unintended results can provide rich sources of learning for future activities and check on current ones.

Evaluations can bring out complementary factors and synergies for development success. For instance, links between the public and private sectors through public-private partnerships (PPPs) could offer new approaches to service delivery and prove to be key to outcomes. Take, for example, PPPs in the agricultural sector. Given the private nature of agricultural activities and the public-good nature of agricultural services, particularly agricultural research and extension, the extent to which 
interventions link government and private producers makes a difference for performance of the agricultural sector.

Transport projects in various settings are seen to improve inclusion if they are linked with programs addressing education and health care. Observations of rural road projects in Bangladesh point to gains when investment takes place in related areas such as education, health, and financial literacy. Yet another example is education policy. Education investment pays off when coupled with labor-market reforms to support job creation, especially for the lower-income strata.

Measurement is another important aspect of evaluation. Independence, objectivity, and the impartiality of data are themselves a big part of the validity and value of evaluations. By setting clearly measurable objectives, analysis can focus on achievements that can be independently verified.

Often, evaluation is thought to be constrained by the lack of adequate data and information. But it is part of the evaluative process to seek and ensure sufficient data that are credible to lead to the evaluability of projects, programs, and interventions. The appearance of big data can be a potential aid to this endeavor, as Chap. 5 suggests.

In development economics, various empirical methods, including econometric analysis, measure the effectiveness of interventions. Evaluation has evolved with some dominant approaches and several strands of analytical methods tailored to specific situations, including qualitative assessments (AEA 2004; ECG 2010; IED 2014).

IE, as elaborated in Chap. 2, measures the change attributable to a program or intervention and tries to answer the question-what difference does the program make? It considers the counterfactual, which could be pre- versus post-program situation, or with and without the intervention. This approach can help assess the effects of programs that seek to ensure greater social inclusion and environmental protection (Croke et al. 2017). The much-cited example is the case of social protection programs, where an evaluation delineates the impacts of conditional cash transfers.

CBA, detailed in Chap. 3, is a long-standing economic tool of analysis especially for infrastructure projects, but it can be put to better and wider use to assess social and environmental projects as well. It does well when data on costs and benefits of the intervention can be gathered, which is usually easier for the so-called hard sectors like infrastructure (see, e.g., Harberger 1976; Boardman et al. 2006). The evaluated projects are either in the public sector or in the private sector. Its framework provides for valuation techniques to account for externalities such as pollution and congestion as well. 
Multilateral development banks heavily use assessments of accomplishments against agreed-on or planned goals, in what is often referred to as objectives-based evaluation, as discussed in Chap. 4. The approach is applied for public sector as well as private sector projects. There are wellestablished criteria to judge project success: relevance, efficiency, effectiveness, development impact, and sustainability (DAC 1991, 2018). Often, ratings on each of these criteria are aggregated to assess overall performance.

The bulk of evaluations have a project and micro, and at most a sectoral and thematic, focus. Cross-linkages and macro-aggregations are not often done, even when actions taken at higher policy levels are decisive factors in individual project-level success. For example, while individual analysis of environmental projects is valuable, the government's environmental regulation might have overriding importance.

If evaluation is to contribute to improving sustainable development outcomes, then it must straddle project and sectoral boundaries and make calls at the macro or aggregative levels. It must assess impacts on aggregative goals such as inclusive growth, environmental care, and good governance. Doing so requires evaluation to work closely with the economics discipline. There are risks in doing so, but the rewards would be high.

Rather than thinking of these tools and disciplines as alternatives, they can be considered as part of a rigorous framework that mixes methods depending on the issues at hand. Crucial to this approach would be the identification of high-priority objectives and issues. IE can be applied more widely than at present, not only to social policies but also to urban development, infrastructure, and climate change policies. We must also take CBA more seriously and not let data limitations discourage its use. OBE would benefit from deepening linkages with economic analysis and incorporating evidence from complementary approaches.

Evaluations and available data often lead to findings that confirm what is known. Here, its value lies mainly in summarizing lessons and, perhaps, in suggesting improvements for future interventions. But some evaluations generate unexpected results that question the assumed connections between actions and desired outcomes, including the critical assumptions and context for the underlying theory of change implicit in the activity.

By pointing out crucial but neglected areas and providing timely information to change development thinking and guide policy decisions, evaluations can push policy interventions from a generally accepted but perhaps ineffective state of inertia to a more beneficial course. There is a premium in evaluation taking on cutting-edge issues in sustainable development, even when data and conceptual aspects constrain the analysis. 


\section{Evaluating Components of THe SDGs}

In the context of sustainable development, Thomas et al. (2000) discussed the need to consider the quality of growth, in addition to its quantity, in terms of social inclusion, environmental stewardship, and the accompanying governance. Sachs (2012) signaled the importance, in addition to economic growth, of inclusion, the environment, and good governance in thinking about sustainable development. The goals and targets under the SDGs can be laid out within these overarching aims. Progress along these axes can be tracked, monitored, and assessed (Kharas et al. 2018).

But these issues present challenges to evaluation. In particular, evaluation priorities and methods have not kept pace with the needs of assessing outcomes in sustainable development. We need to step up evaluation efforts at several levels, improving frameworks; methods of analysis; and relevant and practical applications, conclusions, and recommendations. We now take up some illustrations of how evaluation might view the principal components of the SDGs.

\section{Inclusive Growth}

There is a growing recognition within countries that growth that is inclusive is vital for how it impacts people's well-being and for continuing economic growth itself. Empirical studies suggest that not only does higher inequality tend to limit the impact of growth on absolute poverty but also that countries with high inequality may experience rising poverty despite good growth prospects (Ravallion 1997). Piketty (2014) shows that as economies develop, the uneven distribution of skills and education of the workforce promotes inequality, and inequality continues to increase unless some measures are taken (see also Lakner and Milanovic 2013).

Redistribution policies that use taxes and transfers, while politically sensitive, are still the predominant tools used to address inequality. One way to assess whether redistribution policies promote inclusive growth or not is to distinguish market inequality (before taxes and transfers) from net inequality (after taxes and transfers), as done by Ostry, Berg, and Tsangarides (2014). Their empirical analysis suggests that the impact of redistribution on inclusive growth is generally positive except for countries where difference between the market and net inequality is extremely large (see also Sabot et al. 2016). 
The desire to increase economic growth remains the principal driver of policy, but there are good grounds for building inclusion into the design and implementation of projects intended to help raise economic growth. In the past, social inclusion and environmental protection were viewed as good to have but their pursuit presented unacceptable trade-offs to economic growth. However, some results have shown that projects with objectives incorporating inclusive growth have performed well compared to those that do not (IED 2016).

A review of 94 private sector projects at $\mathrm{ADB}$ since 2006 seems to suggest that development results and investment profitability are not necessarily incompatible. Table 1.1 shows the association (not causality) between a project's profitability and its development results. It suggests that 56 of the 94 projects evaluated ( 60 percent) were rated by the criteria used as both profitable and successful in contributing to development. Earlier exercises done at the World Bank on larger samples showed a similar association (see Chap. 4).

In these private sector interventions, projects have tried to address inclusive growth through two main channels. The majority of them have invested in areas where there is a constraint on inclusive growth. These investments benefit people at the bottom of the pyramid, providing infrastructure and financial services. In addition, there are inclusive business transactions that work with businesses that provide services to the poor, primarily employing people from disadvantaged groups or including the poor in their supply chains.

The recognition of the importance of inclusive growth raises several challenges, an important one being the management of actual or perceived trade-offs. One example is evaluating the cost involved in expanding the reach of education and health services as well as social protection, all of which will aid inclusion. CBA is particularly suited to weigh the additional

Table 1.1 Development results and ADB profitability ratings

\begin{tabular}{|c|c|c|c|}
\hline & \multicolumn{3}{|c|}{ Development results } \\
\hline \multirow[t]{5}{*}{ ADB profitability } & High & 9 & 56 \\
\hline & & $10 \%$ & $60 \%$ \\
\hline & Low & 23 & 6 \\
\hline & & $24 \%$ & $6 \%$ \\
\hline & & Low & High \\
\hline
\end{tabular}

Source: IED (2016) 
expenditures against the stream of benefits accruing from broader participation of people in the growth process.

\section{Environmental Protection}

Environmental protection remains a contentious, complex, and dynamic area with a number of perceived or actual trade-offs to be considered. One example is food security: there is the need to increase areas under cultivation while at the same time ensuring sustainable forest use and conservation. Another example is the pressure to develop fossil-fuel energy to power growth which conflicts with controlling pollution and minimizing damages to human health and mitigating climate change.

However, there is growing evidence that sustained growth will not be possible in the future without tackling environmental degradation and climate change. Climate change is the greatest known threat to sustainable development, and its impacts go far beyond natural disasters (Stern 2006). The costs of climate-related disasters in many disaster-prone countries like Bangladesh, Cuba, Haiti, Thailand, and the Philippines are staggering, and they weigh down on economic growth.

A concern for environmental protection is sometimes seen as an impediment for delivering efficient and effective projects as well as for supporting rapid growth. But evaluation results do not seem to endorse this concern. A review of the success rates of projects with environmentalsafeguards categories shows an interesting association (not causality). Those which needed more substantial environmental safeguards (because of higher risks) performed better in terms of estimated project success rates (Table 1.2). Projects are labeled Category A when they are likely to have significant environmental risks.

These projects require an environmental-impact assessment and an environmental-management plan, as well as an elaborate process of consultation and coordination, bringing higher levels of complexity and risk.

Table 1.2 Success rates by environmental-safeguards category

\begin{tabular}{llll}
\hline & Category $A$ & Category $B$ & Category $C$ \\
\hline Success rate & $84 \%$ & $62 \%$ & $57 \%$ \\
Number of projects rated & 64 & 263 & 166 \\
\hline
\end{tabular}

Source: IED (2016) 
Despite these added challenges, the success rate of these projects is higher than for projects with more limited (Category B) and minimal or no potential environmental impacts (Category C). This may suggest that the extra scrutiny Class A projects get on environmental grounds may have positive spillover effects on the broader design and implementation.

Evaluation of climate change needs to account for more than goods and services that can be monetized. Complementing CBA with additional decision-making tools can make evaluations more comprehensive and provide more robust insights. Many of these tools, such as green accounting methods, are in principle available for better valuations of natural capital. The availability of data is usually a constraint to such valuations. But they are important considering that when the destruction of natural capital is not accounted for, growth prospects are likely inflated.

IE has been applied to assess policies for mitigating climate change and environmental degradation. Examples include an evaluation of Brazil's deforestation control policies, suggesting that when a municipality is designated as a priority, deforestation rates within about 50 kilometers of its boundaries decrease from improved monitoring, but rates farther away increase from displacement of illicit activity (Slough and Urpelainen 2018). Another evaluation of community-based forest management in Ethiopia (Takahashi and Todo 2012) found that the forest area managed by forest associations declined more in the year of establishment than forest areas with no association, perhaps from "last-minute" logging. But on average, the forest area of the forest associations increased by 1.5 percent in the first 2 years, whereas those not managed as part of an association declined by 3.3 percent.

Evaluators have been slow in applying economic evaluation tools to environmental issues, but it is now urgent that the discipline comes to grips with it. It is only with a swift policy response based on sound evidence that countries can highlight and address issues threatening environmental protection and achieve sustainable development.

\section{Institutions and Governance}

There is no universal strategy for pursuing a triple bottom line of growth, inclusion, and environmental protection, but having better institutions and good governance, which cut across all these areas, helps. That puts the evaluations of institutions, corporate structures, incentives, and performance at the center. Global measures of good governance vary a great deal 
across regions and countries and over time (Kaufmann et al. 2009). For example, Southeast Asia fares poorly in its control of corruption, while in East Asia, the gaps are wide for voice and accountability-an indicator which captures perceptions of the extent to which citizens can participate in policy-making processes and the accountability of governments. South Asia, meanwhile, ranks low in political stability.

Good governance could lead to sustainable development through various channels. It plays a critical role in promoting inclusive growth by ensuring that public services actually reach the poor and disadvantaged. Development practitioners know the deleterious effects on health and education of absenteeism of doctors and teachers, especially in remote rural areas. Consider also the crisis of climate change: the elimination of fossil-fuel subsidies has long been advocated as a means to cutting back high-carbon energy and freeing up funding for green-energy projects. However, their implementation comes up against the political economy of such reform.

But there is also evidence that even modest improvements pay off. One review (IEG 2011) indicates that the achievement of country outcomes was correlated with country governance, measured by the Country Policy and Institutional Assessment (CPIA) data. Just four out of nineteen programs in countries with low CPIA governance scores (3.2 or less) had satisfactory outcomes, compared with 75 percent in those with high CPIA governance scores. Generally speaking, when governance is off course, projects seem to do poorly.

Governance projects supported by external financial agencies usually fall into the categories of public sector management (the largest segment), financial management, civil-services reform, and anti-corruption activities. An OBE of the success rates of these projects shows that they generally fall below the overall average performance, signaling the difficulty of working in the governance area (IEG 2008).

Some evidence points to the potential for governance projects to work. IEG 2008 showed a large difference in estimated governance scores between countries that borrowed from the World Bank for public sector reform and those that did not (Table 1.3). Overall, borrowers had a 73 percent improvement rate in terms of countries that improved the CPIA and non-borrowers a 48 percent improvement rate in this estimated governance score. Across regions the correlation of public sector reform lending with changes in governance scores varied sizably. Europe and Central Asia had the highest rate of improvement for countries getting such lend- 
Table 1.3 Public sector reform lending associated with higher governance scores, 1999-2006

\begin{tabular}{llllr}
\hline Region & \multicolumn{2}{l}{$\begin{array}{l}\text { With World Bank public sector } \\
\text { reform lending }\end{array}$} & $\begin{array}{l}\text { Without World Bank public } \\
\text { sector reform lending }\end{array}$ \\
\cline { 2 - 5 } & Percent & Number & Percent & Number \\
\hline Sub-Saharan Africa & 70 & 30 & 47 & 15 \\
East Asia and the Pacific & 70 & 10 & 56 & 9 \\
Europe and Central Asia & 90 & 20 & 86 & 7 \\
Latin America and the & 75 & 20 & 25 & 8 \\
Caribbean & & & & 2 \\
Middle East and North & 57 & 7 & 0 & 1 \\
Africa & 50 & 6 & 0 & 42 \\
South Asia & 73 & 93 & 48 & \\
Total & & & & \\
\hline
\end{tabular}

Source: IEG (2008)

Note: Entries show the percent and number of countries with an improvement in the average CPIA during 1999-2006

ing (90 percent), and the rate of improvement for non-borrowers is almost as high. The explanation might lie elsewhere, for instance, European Union accession.

Service delivery is a key aspect of good governance. Developing mechanisms and harnessing information technology to improve information sharing, transparency, and civic participation have the potential to improve the delivery of services. Recent IEs have attempted to unravel the effect of public service delivery on achievement of the SDGs. Kingdon and Muzammil (2013) find that unionization makes public school teachers less accountable toward student performance and lowers incentives to put in effort on student learning, thus resulting in low test scores. Yamada, Sawada, and Luo (2013) find that improved health service delivery owing to timely payment of wages is negatively associated with absenteeism among public health workers in Lao PDR. Such findings can provide a picture of what needs to be done to improve public service delivery.

\section{ConClusion}

A great deal of progress has been made in applying evaluation tools to the assessment of individual projects, programs, or interventions. Projects and programs remain the building blocks for achieving broad development goals. But there is a gap in linking the economics of these actions with the 
evaluation findings and in connecting the dots to see how overall development goals are being achieved.

This book encourages more integration of economics and evaluation analytics. Historically, the evaluation field grew out of the need to assess social programs and support legislation of the programs, as, for example, in the 1960s in the United States. There has been a focus on psychometrics, surveys, and data, but not the economics of the issues being tackled. The major encounter between economics and evaluation has been in development evaluation, and it has not been an easy one. IE opens the door for a much greater economics-evaluation integration. CBA too has the potential for expanding such connectivity. OBE can provide the platform to integrate methods of economic evaluation with other evaluation techniques for a more comprehensive assessment.

The book also pushes evaluations to go from being value-neutral to embracing a more policy-oriented, and at the same time rigorous, role. To make this transition, evaluations can be done against well-articulated goals, such as the SDGs. It would be valuable to introduce the issues of inclusive growth and environmental protection underpinned by good governance as the three overarching goals encompassing the SDGs. If evaluations were to adopt the SDGs as a measuring rod, it would be possible to get good comparative analysis of what is working in development. Improvements in evaluation techniques are also essential. In particular, evaluation techniques need to be adaptive, sensitive to complexity, and amenable to feedback and replication.

An important goal for achieving sustainable development is capacity building. In the context of evaluation, it refers to developing evaluation capacity not only among established institutions but also among new enterprises on a country-competency level. Contributing toward this goal is the larger objective of this book.

\section{BIBLIOGRAPHY}

AEA (American Evaluation Association). 2004. Guiding Principles for Evaluators. Fairhaven, MA: AEA.

Bamberger, Michael, Jos Vaessen, and Estelle Raimond. 2016. Dealing with Complexity in Development Evaluation: A Practical Approach. California: Sage. Basu, Kaushik, Francois Bourguignon, Justin Yifu Lin, and Joseph E. Stiglitz. 2016. "A New Year's Development Resolution." https://www.project-syndicate.org/commentary/update-development-policy-inequality-bykaushik-basu-et-al-2016-12? barrier=accessreg. 
Boardman, Anthony E., David H. Greenberg, Aidan R. Vining, and David L. Weimer. 2006. Cost-Benefit Analysis: Concepts and Practice, Vol. 3. Upper Saddle River, NJ: Prentice Hall.

Brundtland, Gro Harlem. 1987. Our Common Future: Report of the 1987 World Commission on Environment and Development. Oslo: United Nations.

Cameron, Drew, and Jorge Miranda. 2015. “Trends in Impact Evaluation: Did We Ever Learn?". http://blogs.3ieimpact.org/trends-in-impact-evaluation-didwe-ever-learn/.

Castelló-Climent, Amparo. 2010. "Inequality and Growth in Advanced Economies: An Empirical Investigation." Journal of Economic Inequality 8 (3):293-321.

Cotterman, Ron. 2016. "The Sustainability Paradox: Why Business Leaders Need to Evolve Their Approach." https://sealedair.com/insights/sustainability-par adox? gclid=EAIaIQobChMI6Iqek4K43AIVgTqBCh2bSgiHEAAYAiAA EgIYcfD_BwE.

Croke, Kevin, Eric Hsu, and Michael Kremer. 2017. "More Evidence on the Effects of Deworming: What Lessons Can We Learn?.” American Journal of Tropical Medicine and Hygiene 96 (6):1265-1266.

Dabla-Norris, Era, Kalpana Kochhar, Nujin Suphaphiphat, Frantisek Ricka, and Evridiki Tsounta. 2015. Causes and Consequences of Income Inequality: A Global Perspective, IMF Staff Discussion Note. Washington, DC: International Monetary Fund.

DAC (Development Assistance Committee). 1991. The DAC Principles for the Evaluation of Development Assistance. Paris: OECD.

DAC (Development Assistance Committee). 2018. "DAC Criteria for Evaluating Development Assistance." OECD. http://www.oecd.org/dac/evaluation/ daccriteriaforevaluatingdevelopmentassistance.htm.

ECG (Evaluation Cooperation Group). 2010. Good Practice Standards on Independence of International Financial Institutions' Central Evaluation Departments. Manila: Evaluation Cooperation Group.

Halter, Daniel, Manuel Oechslin, and Josef Zweimüller. 2014. "Inequality and Growth: The Neglected Time Dimension." Journal of Economic Growth 19 (1):81-104.

Hanushek, Eric A., Stephen Machin, and Ludger Woessmann, eds. 2006. Handbook of the Economics of Education. Amsterdam: North Holland.

Harberger, Arnold C. 1976. Project Evaluation: University of Chicago Press.

Heider, Caroline. 2017. "Rethinking Evaluation-Sustaining a Focus on Sustainability." IEG. http://ieg.worldbankgroup.org/blog/rethinking-evaluation-sustaining-focus-sustainability.

IED (Independent Evaluation Department). 2014. Evaluation for Better Results. Manila: ADB.

IED (Independent Evaluation Department). 2016. Annual Evaluation Report. Manila: ADB. 
IEG (Independent Evaluation Group). 2008. Public Sector Reform: What Works and Why-An IEG Evaluation of World Bank Support. Washington DC: World Bank.

IEG (Independent Evaluation Group). 2009. Knowledge for Private Sector Development. Washington DC: World Bank.

IEG (Independent Evaluation Group). 2010. The World Bank Group's Response to Global Economic Crisis (Phase I). Washington DC: World Bank.

IEG (Independent Evaluation Group). 2011. Results and Performance of the World Bank Group: IEG Annual Report 2011. Washington DC: World Bank.

IEG (Independent Evaluation Group). 2012. World Bank Group Response to the Global Economic Crisis. Washington DC: World Bank.

IEO (Independent Evaluation Office). 2014. IMF Response to the Financial and Economic Crisis. Washington DC: International Monetary Fund.

IEU (Independent Evaluation Unit). 2018. Independent Review of the GCF's Results Management Framework, Evaluation Report No. 1/2018. Songdo, South Korea: Green Climate Fund.

IPCC (Intergovernmental Panel on Climate Change). 2014. Climate Change 2014: Impacts, Adaptation, and Vulnerability. Geneva, Switzerland: IPCC.

Kanbur, Ravi. 2016. "Economic Growth and Poverty-the Inequality Connection." https://en.unesco.org/news/ravi-kanbur-economic-growthand-poverty-inequality-connection.

Kaufmann, Daniel, Aart Kraay, and Massimo Mastruzzi. 2009. Governance Matters VIII: Aggregate and Individual Governance Indicators 1996-2008. Policy Research Working Paper no. WPS 4978. Washington DC: World Bank.

Kharas, Homi, John McArthur, and Krista Rasmussn. 2018. "Counting Who Gets Left Behind: Current Trends and Gaps on the Sustainable Development Goals."

Kingdon, Geeta, and Mohd Muzammil. 2013. "The School Governance Environment in Uttar Pradesh, India: Implications for Teacher Accountability and Effort." Journal of Development Studies 49 (2):251-269.

Lakner, Christoph, and Branko Milanovic. 2013. Global Income Distribution: From the Fall of the Berlin Wall to the Great Recession. Policy Research Working Paper no. 6719. Washington DC: World Bank.

Lukauskas, Arvid, Robert M. Stern, and Giani Zanini, eds. 2013. Handbook of Trade Policy for Development. Oxford: Oxford University Press.

McGrail, Stephan. 2014. "Rethinking the Roles of Evaluation in Learning how to Solve 'Wicked' Problems: The Case of Anticipatory Techniques used to Support Climate Change Mitigation and Adaptation." Evaluation Journal of Australasia $14(2): 4-16$.

Morgan, Trevor. 2007. Energy Subsidies: Their Magnitude, How They Affect Energy Investment and Greenhouse Gas Emissions, and Prospects for Reform. Bonn: UNFCCC Financial and Technical Support Programme.

Morra Imas, Linda G., and Ray C. Rist. 2009. The Road to Results: Designing and Conducting Effective Development Evaluations. Washington DC: World Bank Publications. 
O’Connell, Deborah. 2014. "Evaluating Sustainability." https://www.betterevaluation.org/en/blog/evaluating_sustainability.

OECD (Organisation for Economic Co-operation and Development). 2010. Evaluation in Development Agencies. Better Aid. Paris: OECD.

Okun, Arthur M., William Fellner, and Michael Wachter. 1975. "Inflation: Its Mechanics and Welfare Costs." Brookings Papers on Economic Activity 1975 (2):351-401.

Ostry, Jonathan David, Andrew Berg, and Charalambos G. Tsangarides. 2014. Redistribution, Inequality, and Growth. Washington DC: IMF.

OVE (Office of Evaluation and Oversight). 2015. Evaluating Climate Change. Washington DC: Inter-American Development Bank.

Petri, Peter, and Vinod Thomas. 2013. Development Imperatives for the Asian Century. ADB Economics Working Paper no. 360. Manila: ADB.

Picciotto, Robert. 2013. "Evaluation Independence in Organizations." Journal of MultiDisciplinary Evaluation 9 (20):18-32.

Piketty, Thomas. 2014. Capital in the 21st Century. Cambridge, MA: The Belknap Press of Harvard University Press.

Pradhan, Prajal, Luís Costa, Diego Rybski, Wolfgang Lucht, and Jürgen P. Kropp. 2017. "A Systematic Study of Sustainable Development Goal (SDG) Interactions.” Earth's Future 5 (11):1169-1179.

Ravallion, Martin. 1997. "Can High-Inequality Developing Countries Escape Absolute Poverty?” Economics Letters 56 (1):51-57.

Ravallion, Martin. 2009. "Evaluation in the Practice of Development." World Bank Research Observer 24 (1):29-54.

Ravallion, Martin. 2013. How Long Will It Take to Lift One Billion People Out of Poverty? Policy Research Working Paper no. 6325.

Sabet, Shayda Mae, and Annette N. Brown. 2018. "Is Impact Evaluation Still on the Rise? The New Trends in 2010-2015." Journal of Development Effectiveness $10(3): 291-304$.

Sabot, Richard, David Ross, and Nancy Birdsall. 2016. Inequality and Growth Reconsidered: Lessons from East Asia. Working Papers id:8848, eSocialsciences.

Sachs, Jeffrey D. 2012. "From Millennium Development Goals to Sustainable Development Goals.” Lancet 379 (9832):2206-2211.

Shaker, Richard Ross. 2015. "The Spatial Distribution of Development in Europe and its Underlying Sustainability Correlations." Applied Geography 63:304-314.

Slough, Tara, and Johannes Urpelainen. 2018. Public Policy Under Limited State Capacity: Evidence from Deforestation Control in the Brazilian Amazon. mimeo.

Stern, Nicholas Herbert. 2006. The Economics of Climate Change: The Stern Review Cambridge: Cambridge University Press.

Takahashi, Ryo, and Yasuyuki Todo. 2012. "Impact of Community-Based Forest Management on Forest Protection: Evidence from an Aid-Funded Project in Ethiopia." Environmental management 50(3): 396-404. 
Tarsilla, Michele. 2009. "Theorists' Theories of Evaluation: A Conversation with Jennifer Greene." Journal of MultiDisciplinary Evaluation 6 (13):209-219.

Thomas, Vinod, Mansoor Dailimi, Ashok Dhareshwar, Daniel Kaufmann, Nalin Kishor, Ramón López, and Yan Wang. 2000. The Quality of Growth. Washington DC: World Bank.

Thomas, Vinod, and Xubei Luo. 2012. Multilateral Banks and the Development Process: Vital Links in the Results Chain. New Brunswick, NJ: Transaction Publishers.

Tolley, George S. Graves, Philip E., and John L. Gardner. 1979. Urban Growth Policy in a Market Economy. New York: Academic Press.

United Nations. 2015. The Millennium Development Goals Report 2015. New York: United Nations.

United Nations. 2016. Global Sustainable Development Report: Briefs 2015. Geneva: United Nations.

United Nations. 2018. The Sustainable Development Goals Report 2018. New York: United Nations.

World Bank. 1991. World Development Report 1991: The Challenge of Development. Washington DC: World Bank.

World Bank. 2006. Development and the Next Generation. World Development Report 2007. Washington DC: World Bank.

Yamada, Hiroyuki, Yasuyuki Sawada, and Xubei Luo. 2013. "Why is Absenteeism Low among Public Health Workers in Lao PDR?" Journal of Development Studies 49 (1):125-133.

Open Access This chapter is licensed under the terms of the Creative Commons Attribution 4.0 International License (http://creativecommons.org/licenses/ by $/ 4.0 /$ ), which permits use, sharing, adaptation, distribution and reproduction in any medium or format, as long as you give appropriate credit to the original author(s) and the source, provide a link to the Creative Commons licence and indicate if changes were made.

The images or other third party material in this chapter are included in the chapter's Creative Commons licence, unless indicated otherwise in a credit line to the material. If material is not included in the chapter's Creative Commons licence and your intended use is not permitted by statutory regulation or exceeds the permitted use, you will need to obtain permission directly from the copyright holder.

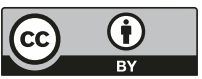

